\title{
Association mapping for photosynthesis and yield traits under two moisture conditions and their drought indices in winter bread wheat (Triticum aestivum L.) using SSR markers
}

\author{
Iqbal Saeed $^{1,2}$, Xiaojie Chen ${ }^{1,3}$, Daoura Goudia Bachir ${ }^{1}$, Liang Chen ${ }^{1}$, Yin-Gang Hu${ }^{1,4 *}$ \\ ${ }^{1}$ State Key Laboratory of Crop Stress Biology for Arid Areas, College of Agronomy, Northwest A\&F University, \\ Yangling, Shaanxi, P.R. China \\ ${ }^{2}$ NIFA, PO Box 446, Tarnab, Peshawar, KP, Pakistan \\ ${ }^{3}$ Henan Key Laboratory of Nucleus Agriculture, Isotope Institute Co Ltd, Henan Academy of Sciences, \\ Zhengzhou 450015, China \\ ${ }^{4}$ Institute of Water Saving Agriculture in Arid Regions of China, Yangling, Shaanxi, 712100, China
}

*Corresponding author: huyingang@nwsuaf.edu.cn

\begin{abstract}
Net photosynthesis rate and drought resistance in wheat need to be improved to enhance overall wheat productivity. Association mapping was used to explore the potential QTLs associated with net photosynthesis rate (Pn), thousand-kernel weight (TKW), biomass plant ${ }^{-1}$ (BMPP) and grain yield plant ${ }^{-1}$ (GYPP) under two water conditions and their drought indices, i.e. stress tolerance index (STI) and stress susceptibility index (SSI) in wheat using 269 whole-genome SSR markers in 59 winter wheat genotypes. Large numbers of marker-trait associations (MTAs) were detected for photosynthesis and yield related traits under both water conditions and related drought tolerance indices in both seasons. However, the number of significant associations reduced greatly when Bonferroni correction (FPDR) test was applied. Single marker, i.e. Xpsp3123-7D was associated with multiple traits across moisture conditions as well as growth seasons. Xgwm182-5D was stably associated with TKW under water-stressed conditions and with GYPP under well-watered conditions, respectively in both seasons. Xcfd33-6D was consistently linked with BMPP in both seasons under well-watered condition. A Total of 28 associations for the drought tolerance indices of those phenotypic traits qualified FPDR test. Of these, Xpsp3123-7D was consistently associated with the two drought indices of the traits in two seasons. The markers Xwmc707-4A and Xgwm182-5D were stably associated with stress susceptibility index (STI) of BMPP and stress tolerance index (STI) of TKW, respectively across two seasons. These putative QTLs, especially Xpsp312-7D can be the key targets to improve photosynthetic efficiency and yield potential of bread wheat in rainfed ecosystem.
\end{abstract}

Keywords: Bread wheat; Photosynthesis; Yield traits; Drought tolerance indices; QTLs; Association mapping.

\section{Introduction}

Wheat is a cereal of choice worldwide and provides onefifth of the total calories consumed by the worlds' population (Reynolds and Pask, 2012). However, global wheat production is negatively affected by both biotic and abiotic stresses and its potential yield is rarely achieved. Drought is one of the major abiotic constraints reducing wheat productivity (Nouri et al., 2011). The anticipated world-wide climate change will elevate temperature, which will further aggravate the situation by accelerating evapo-transpiration losses during the day and increased photorespiration at night (Mir et al., 2012). It is therefore necessary to improve drought resistance for sustainable wheat production.

Genetic improvement in drought tolerance requires identification of traits associated with drought tolerance and introgression of genes underlying the target traits. Latest high-throughput genotyping and phenotyping have helped to understand the physiological and molecular bases of complex traits including drought tolerance (Mir et al., 2012; Sinclair, 2012). QTL mapping using either bi-parental or natural populations is a key approach for understanding the genetic architecture of complex traits in plants. However, QTLs detected using bi-parental populations, might represent only a small portion of the genes controlling the trait and also time consuming to develop suitable mapping populations. The advent of association mapping with natural population has overcome some of the limitations of bi-parental mapping populations. Since association mapping utilizes diverse germplasm, QTLs for many traits can be detected at highresolution in a single study (Neumann et al., 2011; Yu et al., 2009; Breseghello and Sorrells, 2006). Numerous molecular markers have been identified to be associated with different important traits in a wide variety of crops (Wen et al., 2009; Harjes et al., 2008). However, only a few QTL studies have been reported for photosynthetic traits (Wang et al., 2012), probably due to the difficulty in measuring gas exchange parameters under field conditions and the influence of environment on these parameters(Mir et al., 2012).

SSRs have been used as the marker backbone for the localization of individual genes onto the 21 bread wheat chromosomes, including genes affecting traits of economic importance and have been widely used in marker assisted selection in wheat (Ganal and Röder, 2007). Furthermore, wheat SSR markers have been used for the localization of a large set of QTLs for morphologically and agronomically important traits (Huang et al., 2004). After the initial work on the use of SSR makers for kernel traits in hexaploid wheat 
(Snape et al., 2007), various marker-trait associations were identified for disease resistance and yield traits (Peng et al., 2009; Zwart et al., 2008).

Drought resistance of genotypes is usually estimated on the basis of yield reduction under stress relative to yield under non-stress conditions (Fernandez, 1992). Various drought tolerance indices have been widely used for the evaluation and screening of wheat genotypes in order to improve drought resistance (Anwar et al., 2011; Khakwani et al., 2011). The stress susceptibility index (SSI) is used to measure yield stability that apprehends the changes in both potential and actual yield under variable environments (Fischer and Maurer, 1978). SSI of more and less than 1 indicates above and below-average susceptibility to drought stress, respectively (Guttieri et al., 2001). The stress tolerance index (STI) is useful for the identification of genotypes that produce high yield under both stressed and non-stressed conditions (Fernandez, 1992). Little work has been done to detect QTLs associated with drought tolerance indices, especially those based on traits other than grain yield. Detection of such QTLs may be helpful to modulate plant adaptation to drought stress and to devise alternative ways for selection in improving drought tolerance in crop plants.

The main objective of this study was to discover novel marker-trait associations (MTAs) for net photosynthesis rate $(\mathrm{Pn})$, yield components under water-stressed and wellwatered conditions, especially the markers associated with drought tolerance indices based on these traits in wheat through evaluation of a panel of winter bread wheat genotypes using SSR markers.

\section{Results}

\section{Variation in phenotypic traits and drought tolerance indices}

Significant $(P<0.01)$ differences were observed between the two water treatments for the phenotypic traits studied in both seasons (Table 1). The highest mean trait values were recorded under well-watered conditions in both seasons, e.g. the average Pn of 24.42 and $22.73 \mu \mathrm{mol} \mathrm{m}^{-2} \mathrm{~s}^{-1}$ was recorded in 2012-13 and 2013-14, respectively. Similar patterns were also observed for BMPP, TKW and GYPP (Table 1). ANOVA also showed significant $(P<0.01)$ differences among the genotypes for the phenotypic traits under two moisture conditions in both seasons. Genotype Zhonghan 110 showed higher values for most of the traits under both conditions as well as in both seasons followed by genotype Linhan 536 .

The phenotypic traits were significantly $(P<0.05,0.01)$ and positively correlated with each other under both water conditions in both seasons (Table 2). BMPP and GYPP were comparatively strongly correlated with each other in 2012-13 $(\mathrm{r}=0.740)$ and 2013-14 ( $\mathrm{r}=0.631)$ under water-stressed conditions (Table 2), followed by strong correlation between BMPP and TKW $(r=0.631$ in $2012-13$ and $r=0.610$ in 2013-14). Under well-watered conditions in 2012-13, the strongest correlation $(P<0.01)$ was observed between BMPP and GYPP $(\mathrm{r}=0.429)$, whereas in 2013-14, TKW and GYPP were found to be strongly correlated with each other $(\mathrm{r}=$ 0.506) (Table 2).

The two growth seasons did not differ significantly for the drought tolerance indices (STI and SSI) of phenotypic traits (Table 3), whereas significant variations were found among the genotypes for the two indices. The genotype Luohan 6 showed better performance regarding drought tolerance indices for the majority of phenotypic traits in both seasons, with higher STI and lower SSI values for Pn, BMPP, TKW and GYPP.

\section{Population structure and LD among the Genotypes}

The 59 genotypes were assigned to 3 sub-groups (SGs) by STRUCTURE software version 2.3 .3 based on 269 SSR markers (Fig. 1). With the maximum membership probability, 4 genotypes were assigned to SG 1 , of which 3 and 1 genotypes were from Northern and Huang-huai winter wheat regions, respectively; 25 genotypes to SG 2, comprising of 20 genotypes from Northern winter wheat region and 5 from Huang-huai winter wheat region, and 30 genotypes to SG 3, containing 23, 6 and 1 genotypes from Huang-huai, Northern and Southwestern winter wheat regions, respectively.

A total of 36046 marker pairs were detected (Table 4), of which 1670 pairs were found to be linked. Out of 1670 linked pairs, 119 were in LD at $P<0.001$ level, and 19 pairs possessed an $r^{2}$ value greater than 0.1. An LD decay distance around $2.2 \mathrm{cM}$ was estimated for the whole genome, while for $\mathrm{A}, \mathrm{B}$ and $\mathrm{D}$ genomes, the LD decay distances were about 2.2, 0.9 and $8.7 \mathrm{cM}$, respectively (Fig. 2).

\section{Marker-trait associations}

\section{Under water-stressed condition}

In 2012-13, a total of $41,13,22$ and 5 significant $(P<0.05)$ marker-trait associations (MTAs) were detected for Pn, BMPP, TKW and GYPP under water-stressed condition, respectively (Table5; Table S2). After Bonferroni adjustment $(P=0.00019), 3$ QTLs were associated with Pn and 2 QTLs each were associated with BMPP, TKW and GYPP (Table 5). In 2013-14, the number of QTLs significantly associated with Pn, BMPP, TKW and GYPP was 41, 14, 29 and 5 under water stressed condition, respectively (Table 5; Table S3), of which 2 markers each for Pn and TKW, and 1 marker each for BMPP and GYPP qualified the Bonferroni correction test (Table 5).

Single marker i.e. Xpsp3123-7D was significantly associated with all phenotypic traits investigated in both seasons (Table 6) and showed more than $10 \%$ of the total variation $\left(R^{2}\right)$ for the traits (Table 6). Another marker, Xgw182-5D, was associated with TKW in both seasons and explained 11.88 and $11.87 \%$ of the total phenotypic variations for TKW in 2012-13 and 2013-14, respectively. Rests of the significant MTAs were detected for single trait and in single environment. Among these, Xwmc539-2D showed the highest $R^{2}$ value of $26.57 \%$ for BMPP in 2012-13 (Table 6).

\section{Under well-watered condition}

In 2012-13, 54 significant $(P<0.05)$ MTAs were detected for all the phenotypic traits studied under well-watered condition. Out of 54, 4 MTAs for Pn, 3 MTAs for BMPP and 2 MTAs each for TKW and GYPP qualified the Bonferroni correction test (Table5; Table S4). In 2013-14, a total of 30 MTAs were found to be associated with Pn (6 MTAs), BMPP (8 MTAs), TKW (7MTAs) and GYPP (7 MTAs) under well-watered condition (Table S5). Of these, 9 MTAs survived Bonferroni test, including 2 each for Pn, BMPP and TKW, and 3 for GYPP. Among the significant MTAs that qualified Bonferroni correction test, Xpsp3123-7D showed multi-trait associations with stability across growth seasons and explained comparatively higher percentages of the total phenotypic variations $(8.31 \%$ to $15.91 \%)$ in both seasons (Table 7). Markers Xcfd33-6D and Xgwm 182-5D were 
Table 1 Phenotypic traits of 59 bread wheat genotypes under water-stressed and well-watered conditions in two crop seasons.

\begin{tabular}{lccccc}
\hline Trait & Item & $2012-13(\mathrm{WS})$ & $2012-13(\mathrm{WW})$ & $2013-14(\mathrm{WS})$ & $2013-14(\mathrm{WW})$ \\
\hline Pn & Mean & $17.39 \pm 0.48^{\mathrm{B}}$ & $24.42 \pm 0.29^{\mathrm{A}}$ & $18.64 \pm 0.51^{\mathrm{B}}$ & $22.73 \pm 0.24^{\mathrm{A}}$ \\
& Range & $9.12-26.70$ & $18.23-29.10$ & $10.53-23.88$ & $19.04-26.77$ \\
BMPP & Mean & $25.37 \pm 1.81^{\mathrm{B}}$ & $48.69 \pm 1.34^{\mathrm{A}}$ & $30.78 \pm 5.05^{\mathrm{B}}$ & $54.13 \pm 1.53^{\mathrm{A}}$ \\
& Range & $7.80-60.80$ & $24.70-67.70$ & $9.71-67.43$ & $27.13-80.86$ \\
TKW & Mean & $26.75 \pm 1.54^{\mathrm{B}}$ & $43.92 \pm 1.08^{\mathrm{A}}$ & $32.34 \pm 1.85^{\mathrm{B}}$ & $48.48 \pm 1.24^{\mathrm{A}}$ \\
& Range & $10.30-53.40$ & $26.5-61.5$ & $12.48-62.28$ & $28.87-67.02$ \\
GYPP & Mean & $10.63 \pm 0.69^{\mathrm{B}}$ & $21.55 \pm 0.65^{\mathrm{A}}$ & $12.79 \pm 0.83^{\mathrm{B}}$ & $24.06 \pm 0.73^{\mathrm{A}}$ \\
& Range & $3.4-22.90$ & $11.7-38.2$ & $4.01-27.55$ & $13.01-42.56$ \\
\hline
\end{tabular}

WS: water-stressed, WW: well-watered, Pn: net photosynthesis rate $\left(\mu \mathrm{mol} \mathrm{m}^{-2} \mathrm{~s}^{-1}\right)$, BMPP: biomass plant ${ }^{-1}(\mathrm{~g})$, TKW: thousand kernel weight $(\mathrm{g})$, GYPP: grain yield plant ${ }^{-1}(\mathrm{~g})$. Capital letters show significant differences $(P<0.01)$ in the traits between two water treatments.

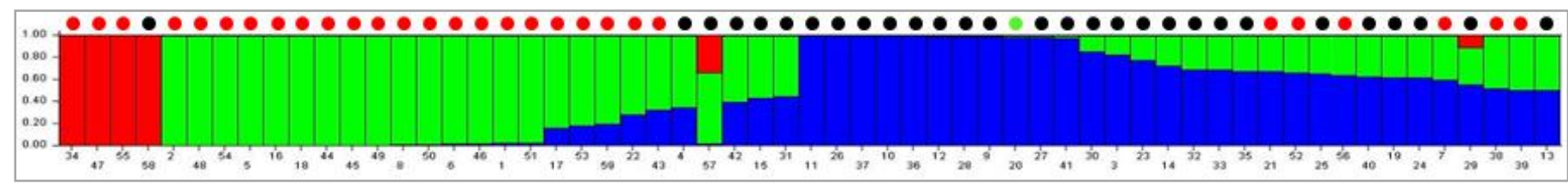

Fig 1. Distribution of 59 genotypes in 3 subgroups based on SSR markers data processed in Structure 2.3.4. The red, green and blue colors correspond to subgroup 1 (SG 1), subgroup 2 (SG 2) and subgroup 3 (SG 3), respectively. The values on the Y-axis correspond to membership coefficients of each genotype and the numbers on the $\mathrm{X}$-axis indicate the code numbers of the genotype as indicated in Table S1. Red spots represent genotypes from Northern winter wheat region; Black spots represent genotypes from Huang-huai winter wheat region; Green spot represents a genotype from Southwestern winter wheat region.

Table 2. Correlation coefficients between phenotypic traits under water-stressed (WS) and well-watered (WW) conditions in 2012 13 (lower left diagonals) and 2013-14 (upper right diagonals) crop seasons.

\begin{tabular}{lccccc}
\hline Treatments & Traits & Pn & BMPP & TKW & GYPP \\
\hline Water-stressed (WS) & Pn & 1 & $0.254^{*}$ & $0.249^{*}$ & $0.259^{*}$ \\
& BMPP & $0.322^{*}$ & 1 & $0.610^{* *}$ & $0.631^{* *}$ \\
& TKW & $0.289^{*}$ & $0.631^{* *}$ & 1 & $0.572^{* *}$ \\
& GYPP & $0.264^{*}$ & $0.740^{* *}$ & $0.600^{* *}$ & 1 \\
\hline Well-watered (WW) & Pn & 1 & $0.310^{*}$ & $0.255^{*}$ & $0.262^{*}$ \\
& BMPP & $0.319^{*}$ & 1 & $0.276^{*}$ & $0.449^{* *}$ \\
& TKW & $0.257^{*}$ & $0.379^{* *}$ & 1 & $0.506^{* *}$ \\
& GYPP & $0.277^{*}$ & $0.429^{* *}$ & $0.480^{* *}$ & 1
\end{tabular}

",** indicate correlations are significant at 0.05 and 0.01 level, respectively. WS: water-stressed; WW: well-watered; Pn: net photosynthesis rate $\left(\mu \mathrm{mol} \mathrm{m}^{-2} \mathrm{~s}^{-1}\right)$; BMPP: biomass plant ${ }^{-1}(\mathrm{~g})$; TKW: thousand-kernel weight $(\mathrm{g})$; GYPP: grain yield plant ${ }^{-1}(\mathrm{~g})$.
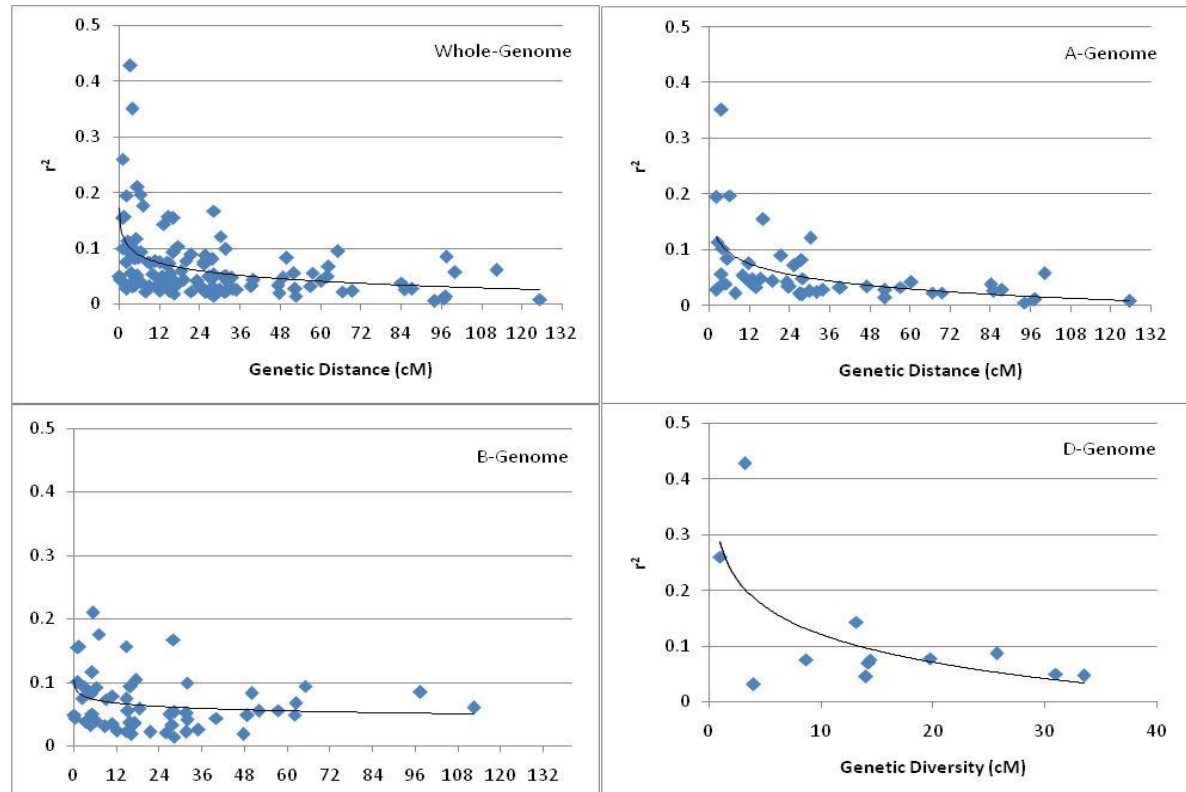

Fig 2. Scatter plots of significant $\mathrm{r}^{2}$ values against genetic distances $(\mathrm{cM})(\mathrm{P}<0.001)$ of marker pairs on whole genome, and $\mathrm{A}$, B, D genome in 59 wheat genotypes 
Table 3. Drought tolerance indices of phenotypic traits of 59 bread wheat genotypes.

\begin{tabular}{lccccc}
\hline \multirow{2}{*}{ Trait } & & \multicolumn{2}{c}{$2012-13$} & \multicolumn{2}{c}{$2013-14$} \\
\cline { 3 - 6 } & Index & Mean & Range & Mean & Range \\
\hline Pn & STI-Pn & $0.80 \pm 0.037 \mathrm{~A}$ & $0.330-2.412$ & $0.766 \pm 0.023 \mathrm{~A}$ & $0.449-1.238$ \\
BMPP & SSI-Pn & $0.99 \pm 0.075 \mathrm{~A}$ & $0.023-2.344$ & $0.998 \pm 0.079 \mathrm{~A}$ & $0.021-2.201$ \\
& STI-BMPP & $0.539 \pm 0.047 \mathrm{~A}$ & $0.109-1.736$ & $0.589 \pm 0.049 \mathrm{~A}$ & $0 / 120-1.778$ \\
TKW & SSI-BMPP & $0.979 \pm 0.070 \mathrm{~A}$ & $0.005-1.742$ & $0.995 \pm 0.077 \mathrm{~A}$ & $0.002-1.896$ \\
& STI-TKW & $0.655 \pm 0.050 \mathrm{~A}$ & $0.157-1.938$ & $0.686 \pm 0.050 \mathrm{~A}$ & $0.170-1.776$ \\
GYPP & SSI-TKW & $0.963 \pm 0.078 \mathrm{~A}$ & $0.117-1.996$ & $0.968 \pm 0.096 \mathrm{~A}$ & $0.032-2.217$ \\
& STI-GYPP & $0.532 \pm 0.046 \mathrm{~A}$ & $0.103-1.719$ & $0.560 \pm 0.048 \mathrm{~A}$ & $0.110-1.849$ \\
& SSI-GYPP & $0.999 \pm 0.053 \mathrm{~A}$ & $0.057-1.638$ & $1.00 \pm 0.660 \mathrm{~A}$ & $0.031-1.749$ \\
\hline
\end{tabular}

Values with similar letters do not differ significantly at $P \leqslant 0.01$ level. Pn: net photosynthes is rate $\left(\mu \mathrm{mol} \mathrm{m}^{-2} \mathrm{~s}^{-1}\right)$; BMPP: biomass plant ${ }^{-1}$ (g); TKW: thousand kernel weight (g); GYPP: grain yield plant ${ }^{-1}(\mathrm{~g})$. STI: stress tolerance index; SSI: stress susceptibility index.

Table 4. Linkage disequilibrium estimation of the SSR marker pairs in 59 winter wheat genotypes.

\begin{tabular}{lcccccc}
\hline & \multicolumn{9}{c}{ Linked locus pairs } & & $\begin{array}{c}\text { Unlinked } \\
\text { locus pairs }\end{array}$ & $\begin{array}{c}\text { Total } \\
\text { locus pairs }\end{array}$ \\
\cline { 1 - 5 } Genome & $\mathrm{A}$ & $\mathrm{B}$ & $\mathrm{D}$ & Whole genome & \\
Observed & 553 & 607 & 510 & 1670 & 34376 & 36046 \\
$\mathrm{P}<0.001, \%$ & $51(9.2 \%)$ & $56(9.2 \%)$ & $12(2.4 \%)$ & $119(7.1 \%)$ & $1026(3 \%)$ & $1145(3.2 \%)$ \\
$\mathrm{P}<0.001, \mathrm{r}^{2}>0.1, \%$ & $7(1.6 \%)$ & $9(1.5 \%)$ & $3(0.6 \%)$ & $19(1.1 \%)$ & $127(0.37 \%)$ & $151(0.42 \%)$ \\
\hline
\end{tabular}

Table 5. Summary of significant MTAs for phenotypic traits under water-stressed and well-watered conditions during two crop seasons.

\begin{tabular}{lcccc}
\hline Trait & $2012-13(\mathrm{WS})$ & $2013-14(\mathrm{WS})$ & $2012-13(\mathrm{WW})$ & $2013-14(\mathrm{WW})$ \\
\hline Pn & $41(3)$ & $41(2)$ & $30(4)$ & $6(2)$ \\
BMPP & $13(2)$ & $14(1)$ & $8(3)$ & $8(2)$ \\
TKW & $22(2)$ & $29(2)$ & $8(2)$ & $9(2)$ \\
GYPP & $5(2)$ & $5(1)$ & $8(2)$ & $7(3)$ \\
\hline
\end{tabular}

The numbers in brackets show significant MTAs after Bonferroni correction threshold $(P=0.00019)$. WS: water-stressed; WW: well-watered; MTA associations; Pn: net photosynthes is rate $\left(\mu \mathrm{mol} \mathrm{m}^{-2} \mathrm{~s}^{-1}\right)$; BMPP: biomass plant ${ }^{-1}(\mathrm{~g})$; TKW: thousand kernel weight $(\mathrm{g})$; GYPP: grain yield plant ${ }^{-1}(\mathrm{~g})$.

Table 6. Marker-trait association for phenotypic traits under water-stressed condition during two crop seasons after Bonferroni correction.

\begin{tabular}{|c|c|c|c|c|c|c|}
\hline \multirow[b]{2}{*}{ Trait } & \multicolumn{3}{|c|}{$2012-13(\mathrm{WS})$} & \multicolumn{3}{|c|}{ 2013-14 (WS) } \\
\hline & Marker & $P$ value & $R^{2}(\%)$ & Marker & $P$ value & $R^{2}(\%)$ \\
\hline \multirow{3}{*}{ Pn } & Xpsp3123-7D & 0.000111 & 15.22 & Xpsp3123-7D & 0.000109 & 14.48 \\
\hline & Xwmc311-7B & 0.000116 & 12.23 & Xwmc732-1D & 0.000113 & 17.16 \\
\hline & Xwmc693-3B & 0.000118 & 18.84 & & & \\
\hline \multirow{2}{*}{ BMPP } & Xpsp3123-7D & 0.00012 & 18.1 & Xpsp3123-7D & 0.00011 & 17.87 \\
\hline & Xwmc539-2D & 0.00011 & 26.57 & & & \\
\hline \multirow{2}{*}{ TKW } & Xgwm182-5D & 0.000113 & 11.88 & Xgwm182-5D & 0.000114 & 11.87 \\
\hline & Xpsp3123-7D & 0.000112 & 15.06 & Xpsp3123-7D & 0.00013 & 15.07 \\
\hline \multirow{2}{*}{ GYPP } & Xpsp3123-7D & 0.000011 & 14.26 & Xpsp3123-7D & 0.000112 & 14.28 \\
\hline & Xwmc407-2A & 0.00012 & 12.46 & & & \\
\hline
\end{tabular}

Associations were considered significant after Bonferroni threshold (0.00019) at $P<0.05$ level. WS: water-stressed; Pn: net photosynthesis rate $\left(\mu\right.$ mol $\left.\mathrm{m}^{-2} \mathrm{~s}^{-1}\right)$; BMPP biomass plant ${ }^{-1}(\mathrm{~g})$; TKW: thousand kernel weight $(\mathrm{g})$; GYPP: grain yield plant ${ }^{-1}(\mathrm{~g})$.

Table 7. Marker-trait associations for phenotypic traits under well-watered condition during two crop seasons.

\begin{tabular}{|c|c|c|c|c|c|c|}
\hline \multirow[b]{2}{*}{ Trait } & \multicolumn{3}{|c|}{$2012-13(\mathrm{WW})$} & \multicolumn{3}{|c|}{ 2013-14 (WW) } \\
\hline & Marker & $P$ value & $R^{2}(\%)$ & Marker & $P$ value & $R^{2}(\%)$ \\
\hline \multirow{4}{*}{ Pn } & Xwmc652-4B & 0.000113 & 12.58 & Xbarc134-6B & 0.000118 & 8.47 \\
\hline & Xpsp3123-7D & 0.00011 & 13.16 & Xpsp3123-7D & 0.00012 & 15.91 \\
\hline & Xbarc260-7D & 0.00014 & 9.74 & & & \\
\hline & Xgwm186-5A & 0.00014 & 15.21 & & & \\
\hline \multirow{3}{*}{ BMPP } & Xcfd33-6D & 0.000142 & 7.76 & Xcfd33-6D & 0.00014 & 7.76 \\
\hline & Xwmc486-6B & 0.000133 & 8.31 & Xpsp3123-7D & 0.000121 & 8.32 \\
\hline & Xpsp3123-7D & 0.000123 & 8.93 & & & \\
\hline \multirow{2}{*}{ TKW } & Xcfd33-6D & 0.00011 & 7.76 & Xpsp3123-7D & 0.000011 & 8.92 \\
\hline & Xpsp3123-7D & 0.000112 & 8.31 & Xwmc376-5B & 0.000114 & 8.29 \\
\hline \multirow{3}{*}{ GYPP } & Xpsp3123-7D & 0.000113 & 11.95 & Xpsp3123-7D & 0.000113 & 12 \\
\hline & Xgwm182-5D & 0.00013 & 9.02 & Xgwm182-5D & 0.000141 & 9.05 \\
\hline & & & & Xcfd189-5D & $1.21 \mathrm{E}-05$ & 6.88 \\
\hline
\end{tabular}

Associations were considered signific ant after Bonferroni threshold (0.00019) at 0.05 level. WW: well-watered; Pn: net photosynthes is rate $\left(\mu \mathrm{mol}^{-2} \mathrm{~s}^{-1}\right)$; BMPP: biomass plant $^{-1}(\mathrm{~g})$; TKW: thousand kernel weight $(\mathrm{g})$; GYPP: grain yield plant ${ }^{-1}(\mathrm{~g})$ 
Table 8. Summary of Significant MTAs for drought tolerance indices of phenotypic traits during two crop seasons.

\begin{tabular}{lcc}
\hline Trait-Indices & $2012-13$ & $2013-14$ \\
\hline Pn-STI & $38(3)$ & $32(2)$ \\
Pn-SSI & $43(2)$ & $34(2)$ \\
\hline BMPP-STI & $19(3)$ & $22(2)$ \\
BMPP-SSI & $9(1)$ & $7(1)$ \\
\hline TKW-STI & $14(2)$ & $13(2)$ \\
TKW-SSI & $27(1)$ & $23(2)$ \\
\hline GYPP-STI & $10(1)$ & $9(1)$ \\
GYPP-SSI & $4(2)$ & $4(1)$ \\
\hline
\end{tabular}

The numbers in brackets show significant MTAs after Bonferroni correction threshold (0.00019). WS: water-stressed; WW: well-watered; Pn: net photosynthesis rate $\left(\mu \mathrm{mol} \mathrm{m}^{-2} \mathrm{~s}^{-1}\right)$; BMPP: biomass plant ${ }^{-1}(\mathrm{~g})$; TKW: thousand kernel weight $(\mathrm{g})$; GYPP: grain yield plant ${ }^{-1}(\mathrm{~g})$; MT As: marker-trait association; STI: stress tolerance index; SSI: stress susceptibility index.

Table 9. Significant MTAs for drought tolerance indices of phenotypic traits during two crop seasons.

\begin{tabular}{|c|c|c|c|c|c|c|}
\hline & \multicolumn{3}{|c|}{$2012-13$} & \multicolumn{3}{|c|}{ 2013-14 } \\
\hline Trait-Indices & Marker & $P$ value & $\mathrm{R}^{2}(\%)$ & Marker & $P$ value & $\mathrm{R}^{2}(\%)$ \\
\hline \multirow[t]{3}{*}{ Pn-STI } & Xpsp3123-7D & 0.000121 & 15.78 & Xpsp3123-7D & 0.00026 & 13.92 \\
\hline & Xwmc693-3B & 0.00011 & 18.77 & Xwmc272-2B & 0.000937 & 17.21 \\
\hline & Xwmc311-7B & 0.00013 & 11.88 & & & \\
\hline \multirow[t]{2}{*}{ Pn-SSI } & Xwmc553-6A & $1.16 \mathrm{E}-05$ & 13.13 & Xpsp3123-7D & $9.01 \mathrm{E}-05$ & 13.64 \\
\hline & Xpsp3123-7D & 0.00012 & 12.71 & Xwmc732-1D & 0.000101 & 14.23 \\
\hline \multirow[t]{3}{*}{ BMPP-STI } & Xwmc707-4A & $7.25 \mathrm{E}-05$ & 22.87 & Xwmc707-4A & $1.14 \mathrm{E}-05$ & 25.2 \\
\hline & Xwmc577-5A & 0.00011 & 9.45 & Xpsp3123-7D & 0.000011 & 14.16 \\
\hline & Xpsp3123-7D & 0.0001 & 13.06 & & & \\
\hline BMPP-SSI & Xpsp3123-7D & 0.00012 & 15.1 & Xpsp3123-7D & 0.000103 & 12.03 \\
\hline \multirow[t]{2}{*}{ TKW-STI } & Xpsp3123-7D & 0.000113 & 12.59 & Xgwm182-5D & 0.000104 & 12.02 \\
\hline & Xgwm 182-5D & 0.00012 & 11.72 & Xpsp3123-7D & 0.00013 & 15.24 \\
\hline \multirow[t]{2}{*}{ TKW-SSI } & Xpsp3123-7D & 0.000012 & 17 & Xpsp3123-7D & 0.000103 & 16.83 \\
\hline & & & & Xwmc428-3A & 0.000105 & 12.22 \\
\hline GYPP-STI & Xpsp3123-7D & 0.000012 & 12.2 & Xpsp3123-7D & 0.00012 & 12.45 \\
\hline \multirow[t]{2}{*}{ GYPP-SSI } & Xgwm508-6D & 0.00013 & 7.13 & Xpsp3123-7D & 0.00012 & 12.95 \\
\hline & Xpsp3123-7D & 0.00011 & 13.44 & & & \\
\hline
\end{tabular}

Associations were considered significant after Bonferroni's threshold (0.00019) at 0.05 level. WS: water-stressed; WW: well-watered; Pn: net photosynthes is rate ( $\mu$ mol $\mathrm{m}$ $\left.{ }^{2} \mathrm{~s}^{-1}\right)$; BMPP: biomass plant ${ }^{-1}(\mathrm{~g})$; TKW: thousand kernel weight (g); GYPP: grain yield plant ${ }^{-1}(\mathrm{~g})$; MT As: marker-trait association; STI: stress tolerance index; SSI: stress susceptibility index.

consistently associated with BMPP and GYPP, respectively in the two seasons. The other 6 markers showed single-trait and environment-specific associations. Of these, a higher effect in terms of percentage of the total phenotypic variation $(15.21 \%)$ for Pn was shown by Xgwm186-5A (Table 7).

\section{Marker-trait associations for drought tolerance indices of phenotypic traits}

Significant $(P<0.05)$ MTAs detected for the drought tolerance indices of the phenotypic traits (STI and SSI) in two growth seasons are presented in Table8 and Tables S6-9. After applying Bonferroni corrects test, 3 and 2 markers showed significant associations with Pn-STI and Pn-SSI, respectively; 3 and 1 markers with BMPP-STI and BMPPSSI, respectively; 2 markers with TKW-STI and 1 marker with TKW-SSI, and 1 and 2 markers with GYPP-STI and GYPP-SSI, respectively in 2012-13. In 2013-14, a total of 13 significant MTAs were detected for the two drought tolerance indices when subjected to Bonferroni correction test. Of these, 2 markers each were associated with Pn-STI and Pn-SSI, 2 and 1 markers were associated with BMPP-STI and BMPPSSI, respectively; 2 markers each with TKW-STI and TKWSSI, and 1 marker each with GYPP-STI and GYPP-SSI (Table 8). Single marker (Xpsp3123-7D) was associated with STI and SSI of all traits in the two seasons. Another marker, Xwmc707-4A, showed consistent association with BMPPSTI in the two seasons, whereas Xgwm182-5D was associated with TKW-STI in both seasons (Table 9). In 2012-
13, 3 markers (Xpsp3123-7D, Xwmc693-3B and Xwmc3117B) contributed more than $10 \%$ of the total phenotypic variation for Pn-STI and Pn-SSI (11.8\% to $15.78 \%)$. Marker Xwmc553-6A showed the strongest association with Pn-SSI and explained $13.13 \%$ of total phenotypic variation. Among the 3 MTAs for BMPP-STI, Xwmc707-4A explained the highest percentage $(22.87 \%)$ of total phenotypic variation.. For STI and SSI of TKW and GYPP, higher contribution was made by Xpsp3123-7Dand explained $12.59 \%$ and $17 \%$ of total the phenotypic variations for TKW-STI and TKW-SSI, respectively, and $12.2 \%$ for GYPP-STI and $13.44 \%$ for GYPP-SSI (Table 9). In 2013-14, 2 markers each associated with Pn-STI (Xpsp3123-7D and Xwmc272-2B) and Pn-SSI (Xpsp3123-7Dand Xwmc732-1D) showed more than 10\% of the total phenotypic variations for the two indices ranging from $13.64 \%$ by Xpsp3123-7D for Pn-SSI to $17.21 \%$ by Xwmc272-2B for Pn-STI (Table9). For BMPP, higher effect in terms of percentage of the total phenotypic variation was shown by Xwmc707-4A for BMPP-STI (25.2\%), whereas the single marker associated with BMPP-SSI i.e. Xpsp3123-7D had an $R^{2}$ value of $12.03 \%$. For TKW and GYPP, Xpsp31237D showed association with the two indices and also affected TKW-SSI to a greater extent in terms of $R^{2}(16.83 \%)$. Among the significant MTAs for the two drought tolerance indices of Pn, BMPP, TKW and GYPP, Xwmc707-4A had the highest $R^{2}$ values of $22.87 \%$ and $25.2 \%$ for BMPP-STI in 2012-13 and 2013-14, respectively (Table 9). 


\section{Discussion}

Determination of population structure and estimation of $L D$ decay distances

Determination of population structure is crucial in association mapping to avoid false associations between markers and traits if not taken into account. The presence of population stratification and an unequal distribution of alleles within groups can result in spurious associations (Flint-Garcia et al., 2003). Based on maximum membership probability, 4 genotypes were assigned to SG 1, 25 to SG 2, and 30 to SG 3 (Fig. 3). The estimation of LD decay distances is of primary importance in association analysis. Different LD decay distances have been reported in wheat. A study by Chao et al., (2007) reported genome-wide LD decay distances of less than $1 \mathrm{cM}$ in U.S wheat cultivars using SSR markers. In the present study, different LD decay distances were estimated for A, B and D genomes (2.2, 0.9 and $8.7 \mathrm{cM}$, respectively). The D-genome exhibited the highest extent of LD decay distance as compared to A and B genomes. Similar results were also reported in a previous study on wheat genotypes (Chao et al., 2010). More extended LD decay distance in the D-genome than in the A and B genomes could be due to the introduction of new haplotype, which can increase the extent of LD from Aegilops tauschii (D-genome donor) into the Dgenome of hexaploid wheat.

\section{Markers associated with net photosynthesis rate (Pn)}

Because of the primary importance of photosynthesis in crop growth, identifying QTLs linked with photosynthesis is an important step in efficient MAS for improved yield (Gu et al., 2011). This assertion is further supported by growing evidence regarding the existence of genetic variation for photosynthesis rates in the available germplasm and that yield progress in cereals is associated with improved photosynthesis (Fischer and Edmeades, 2010). However, little efforts have been undertaken to locate QTLs for photosynthesis and related traits in wheat, especially under water-stressed conditions. In the present study, a total of 5 markers under water-stressed and 6 markers under wellwatered conditions were associated with $\mathrm{Pn}$ in the two growth seasons after application of Bonferroni correction test (Table 6\&7) with higher percentages of the total phenotypic variations for the traits. The results are in keeping with the general observation of Flint-Garcia et al. (2005) that a QTL characterized by a $10 \% R^{2}$ value is defined as a 'major QTL' when detected by AM analysis. This suggests considerable role of the markers identified in the present study as major genetic determinants of photosynthetic efficiency in wheat under variable moisture conditions. None of the markers found associated with Pn in present study have been reported elsewhere previously. However, few researchers such as Li et al. (2014); Habash et al. (2007); Quarrie et al. (2005) reported QTLs associated with indirect predictors of photosynthesis e.g. Fv/Fm, SPAD etc in B genome of wheat. In our case, most of the QTLs associated with Pn were also located in B genome. These markers may therefore be utilized as new sources of genetic markers for potential utilization in MAS after proper validation.

\section{Markers associated with biomass plant ${ }^{-1}(\mathrm{BMPP})$}

Increasing the yield of aerial parts of wheat cultivars is becoming an integral part of wheat breeding programs, and genetic associations between wheat biomass and grain yield have been reported (Maccaferri et al., 2008). However, little information is available about research work on identification of QTLs linked with biomass, although plant biomass has been shown to be important for grain yield in stressed environments (McIntyre et al., 2010). In the present investigation, a total of 3 markers under water-stressed conditions in 2012-13 and 2013-14, and 5 markers under well-watered conditions in the two growth seasons were associated with BMPP after Bonferroni adjustment (Table 6\&7). Markers Xpsp3123-7D and Xwmc539-2D under water-stressed conditions, showed $R^{2}$ values of more than $10 \%$ (18.1\% and $26.57 \%$, respectively) and might be the major QTLs for plant biomass. Marker Xwmc539-2D which explained the highest percentage of the total phenotypic variation $(26.57 \%)$ under water-stressed conditions was also previously reported as a major QTL for wheat biomass in contrasting environment (Osipova et al., 2016), indicating its important role in controlling plant biomass. Marker Xpsp3123-7D was consistently associated with BMPP in both environments and may therefore be efficiently utilized to improve plant biomass in common wheat under variable moisture conditions. However, further evaluation is needed to be carried-out in a wider collection of germplasm and in broader range of environments.

\section{Markers associated with thousand-kernel weight (TKW)}

TKW has direct effect on wheat yield (Gulmezoglu et al., 2010) and its influence on grain yield under contrasting environments seems to cause from the fact that grain yield in wheat is frequently the sink limited (Fischer, 1985). For this reason, TKW has been reported as a promising trait in increasing wheat grain yield under irrigated and dryland conditions. In the present study, significant and positive association of TKW with grain yield was found under both moisture conditions (Table 2). Due to the complex nature of drought, phenotypic selection for traits may be erroneous and time consuming, and search for QTLs controlling phenotypic traits could provide a fast and reliable alternative. Some researchers in the past have detected QTLs for TKW in wheat under both water-stressed and well-watered conditions (Nezhad et al., 2012; Sun et al., 2009; McCartney et al., 2005). In the present study, a total of 8 markers were significantly associated with TKW under both moisture conditions in two growth seasons. Of these, Xpsp3123-7D and Xgwm182-5D had a major effect on TKW under waterstressed conditions with $R^{2}$ values ranging from $11.87 \%$ to $15.07 \%$ in both season. None of the QTLs found associated with TKW in the present research work have been reported for TKW in previous association mapping studies. These genomic regions, especially Xpsp3123-7D and Xgwm182$5 \mathrm{D}$ with higher contribution for the trait, can be the potential loci for TKW under water-stressed and well-watered conditions and may be utilized in marker-assisted breeding in common wheat after validation.

\section{Markers associated with grain yield plant ${ }^{-1}$ (GYPP)}

Genetic architecture of grain yield in bread wheat is of complex nature and is influenced by a large number of major and minor QTLs (Habash et al., 2007). In the context of moisture shortage, a better knowledge of the genetic make-up of yield is an essential prerequisite for effective breeding activities (Salekdeh et al., 2009). Accordingly, genomics approaches facilitate the identification and selection of chromosomal regions harboring genes/QTLs for agronomic traits and yield in crops (Cooper et al., 2009; Collins et al., 
2008). In the current study, number of markers associated with GYPP under water-stressed conditions was less than those under well-watered conditions (Table 6\&7). These results are in keeping with those of Maccaferri et al. (2011) who also reported a decreasing trend under stressed environments. The percentage of the total phenotypic variation explained by the markers associated with GYPP (was higher $(12.46 \%$ to $14.46 \%)$ under water-stressed conditions indicating the profound effects of these genomic regions on the control of grain yield under stressed environments. These markers have not been previously reported for grain yield under either water regime and may therefore be exploited as new potential marker sources to improve grain yield of common wheat under both wellwatered and water-stressed conditions.

\section{Markers associated with drought tolerance indices of the phenotypic traits}

Due to complex nature of agricultural drought, direct trait selection in the field sometimes becomes erroneous and an indirect criterion is therefore needed to be adopted. Various drought tolerance indices have been widely used for the evaluation and screening of wheat genotypes for the improvement of drought tolerance (Anwar et al., 2011; Khakwani et al., 2011). Among these indices, stress tolerance index (STI) and stress susceptibility index (SSI) are important to identify better performing genotypes under both well-watered and water-stressed conditions. These indices can be utilized as alternate selection criteria for traits related to plant development in stressed environments. Few studies such as those of Edae et al. (2014); Dodig et al. (2012), have previously been undertaken to identify QTLs for the drought tolerance indices based on grain yield and few vegetation traits in common wheat, whereas no information is available regarding drought tolerance indices based on Pn, BMPP and TKW in bread wheat. In the present investigation, AM analysis was carried-out to find QTLs associated with SSI and STI of the phenotypic traits so as to find the genetic factors responsible for the control of plant development under stressed environments and their possible use in future breeding of bread wheat. Based on stringent Bonferroni threshold $(P=0.00019), 5$ and 4 MTAs for Pn-STI and PnSSI, respectively; 5 QTLs for BMPP-STI and 2 for BMPPSSI; 4 and 3 MTAs for TKW-STI and TKW-SSI, respectively; and 5 MTAs (2 for STI and 3 for SSI) of GYPP were detected (Table 9). Most of the markers linked with the indices explained more than $10 \%$ of the total phenotypic variation (11.88\% to $22.87 \%$ ) indicating their potential use as major QTLs with indirect control on their respective phenotypic traits. Based on strict significance criterion and non-availability of information elsewhere in previous association mapping studies for drought tolerance in common wheat, these markers can be utilized as new loci for modulation of plant development. However, further investigations are needed to verify the potential of these QTLs in a broad range of contrasting water conditions.

Identifying QTLs related to plant-development with consistency across different environments as well as different genetic backgrounds will help in developing high-yielding crop varieties (Prince et al., 2015). Maccaferri et al. (2008) also emphasized the consistency of a QTL across a broad range of environmental conditions, and that the coincidence of QTLs across environments is critical to breed crops for wide adaptation and yield stability (Cattivelliet al., 2008). Therefore, detection of genomic regions associated with multiple traits across variable environments may increase
QTL pyramiding efficiency. In the present study, Xgwm1825D was associated with TKW under water-stressed conditions in 2012-13 and with GYPP under well-watered conditions in 2013-14 (Table 6\&7), although it's contribution to the total phenotypic variation was considerably low (9.05\%) under well-watered condition. Furthermore, the same QTL was not consistently associated with other phenotypic traits or their respective indices under either moisture conditions. However, this marker may be utilized as potential locus for the improvement of TKW as well as GYPP across contrasting water regimes. Another marker, Xpsp3123-7D was consistently linked with all the phenotypic traits and their respective indices (STI and SSI) with $R^{2}$ values of more than $10 \%$ in most cases. The same marker also showed consistency under both moisture conditions in both crop seasons (Table 6, 7\&9). This genomic marker can be of greater agronomic importance and may therefore be utilized as a new genetic factor for the improvement of photosynthesis and yield traits under a range of agrometeorological conditions.

\section{Materials and Methods}

\section{Plant material and experimental conditions}

A panel of 59 winter wheat genotypes (Table S1) from major wheat growing regions of China was used in the present study comprising of 29 genotypes each from the Northern and Huang-huai Winter Wheat Region and 1 genotype from Southwestern Winter Wheat Region. The experiment was carried out in a rainout shelter at the Institute of Water Saving Agriculture in Arid Regions of China, Northwest A\&F University, Yangling $\left(34^{\circ} 17.7^{\prime} \mathrm{N}, 108^{\circ} 4.05^{\prime}\right.$ E), Shaanxi, P.R. China, during 2012-13 and 2013-14 crop seasons. Two-factor split-plot design with two replications was used with water treatments as the main plots and genotypes as subplots. Each plot in each replication was consisted of two rows of 1.5 meters in length, $25 \mathrm{~cm}$ apart and seeds were sown by hand at an interval of $6.7 \mathrm{~cm}$. The plots were irrigated before sowing to ensure seed germination. To impose drought stress, water was with-held from the plots in water-stressed treatment when most of the genotypes were at the tillering stage and remained till crop maturity. Irrigated plots were watered manually as and when needed.

\section{Phenotypic evaluation and calculation of drought tolerance indices}

Net photosynthesis rate (Pn) was determined on flag leaves of 5 randomly selected plants in each plot of each replication at anthesis (Z67) and grain-filling (Z73) stages using LICOR LI6400XT portable photosynthesis system. The leaf chamber's conditions were set as; reference $\mathrm{CO}_{2}$ concentration $=400 \mu \mathrm{mol} \mathrm{mol}{ }^{-1}, \mathrm{PPFD}=1800 \mu \mathrm{mol} \mathrm{m} \mathrm{m}^{-2} \mathrm{~s}^{-1}$, relative humidity $=50-70 \%$ and block temperature $=20^{\circ} \mathrm{C}$. The measurements were taken between 9:00 and 11:00 am under sunny and windless conditions.

At maturity, 10 plants from each plot and each replication were randomly selected and above-ground plant parts were harvested, dried and weighed using electronic balance and biomass plant $^{-1}$ (BMPP) was subsequently estimated. The same 10 plants were then threshed to record grain yield plant 1 (GYPP). A representative sample of one thousand kernels was taken and thousand-kernel weight (TKW) in $g$ was recorded. Mean data of biomass plant ${ }^{-1}$ (BMPP), grain yieldplant $^{-1}$ (GYPP) and thousand-kernel weight (TKW) was used for subsequent analysis. 


\section{Genotyping with SSR markers}

Genomic DNA was extracted through CTAB procedure (Saghai-Maroof et al., 1984). Genotyping was carried-out using 269 SSR markers distributed across whole-genome, which were selected from the GrainGenes database (http://wheat.pw.usda.gov/GG2). PCR reactions were carriedout as, initial denaturation at $95^{\circ} \mathrm{C}$ for 5 minutes, 35 cycles at $94{ }^{\circ} \mathrm{C}$ for $40 \mathrm{sec}$, optimum annealing temperatures for respective primer pairs for $40 \mathrm{sec}$., $72{ }^{\circ} \mathrm{C}$ for 1 minute and final extension at $72{ }^{\circ} \mathrm{C}$ for 10 minutes. PCR products were separated by $8 \%$ polyacrylamide gel electrophoresis (PAGE) and visualized through silver staining. For each SSR loci, polymorphic bands were scored as 1 for presence and 0 for absence of the bands at the same mobility, respectively.

\section{Data analysis}

Analyses of variance (ANOVA) for the phenotypic data under well-watered and water-stressed conditions in 2012-13 and 2013-14 crop seasons were conducted using Statistical Analysis System (SAS Institute, 2001).

Two drought tolerance indices i.e. STI, SSI of Pn, BMPP, TKW and GYPP were estimated following the methods described below;

Stress tolerance index: $S T I=\frac{Y p \times Y S}{\bar{Y} p^{2}}($ Fernandez, 1992)

Stress susceptibility index $=S S I=\left(1-\frac{Y s}{Y p}\right) / S I ; S I=1-\frac{\bar{Y} \mathrm{~s}}{\bar{Y} p}$

(Fischer and Maurer, 1978)

Where $Y p$ and $Y s$ are the trait value of each genotype, $\bar{Y} p$ and $\bar{Y}_{\mathrm{S}}$ are the means of trait value of all genotypes under waterstressed and well-watered conditions, respectively.

\section{Marker-trait association analysis}

Marker-trait association analysis was carried-out through TASSEL version3.0 (Bradbury, 2007) using MLM model. Population structure was determined through STRUCTURE version 2.3.3 (Pritchard et al., 2000) using admixture model. Length of burn-in period and MCMC replications were 20,000 and 200,000, respectively. The optimum K was estimated using Structure Harvester (Earl and von Holdt, 2012). Kinship matrix of genetic relatedness among pair-wise genotypes was generated using SPAGeDi software (Hardy and Vekemans, 2002). LD estimates for marker pairs were worked-out through TASSEL version 3.0 (Bradbury et al., 2007). LD decay was calculated according to Breseghello and Sorrells (2006). Scatter plots of LD decay distances were generated using SPSS18.0 (SPSS Inc., 2007). Significant MTAs are reported based on Bonferroni threshold which was $0.05 / 269=0.00019$, where 269 is the number of association tests for each trait in the present study.

\section{Conclusion}

New environment-specific as well as across-environment marker-trait associations were detected on different chromosomes. Marker Xpsp3123 on chromosome 7D was associated with all phenotypic traits under both water conditions and both seasons as well as the drought tolerance indices with high percentage of the total phenotypic variation for most of the traits. These putative QTLs with emphasis on Xpsp3123-7D can be the key targets to improve photosynthetic efficiency and may be utilized to breed high- yielding wheat genotypes especially for rainfed wheat ecosystem. However, further investigations are needed in a wider collection of wheat genotypes and in more diverse environments for their final use in marker-assisted breeding in common wheat.

\section{Acknowledgement}

This work was supported by the sub-project of the 863 Program (2013AA102902) of the Ministry of Science and Technology, and the China 111 Project (B12007), P. R. China.

\section{References}

Anwar J, Subhani GM, Hussain M, Ahmad J, Munir M (2011) Drought tolerance indices and their correlation with yield in exotic wheat genotypes. Pak J Bot. 43(3):1527-1530.

Bradbury PJ, Zhang Z, Kroon DE, Casstevens TM, Ramdoss Y, Buckler ES (2007) TASSEL: software for association mapping of complex traits in diverse samples. Bioinformatics. 23:2633-2635.

Breseghello F, Sorrells ME (2006) Association mapping of kernel size and milling quality in wheat (Triticum aestivum L.) cultivars. Genetics. 172(2):1165-1177.

Cattivelli L, Rizza F, Badeck FW, Mazzucotelli E, Mastrangelo AM, Francia E, Mare C, Tondelli A, Stanca AM (2008) Drought tolerance improvement in crop plants: an integrated view from breeding to genomics. Field Crop Res.105:1-14.

Chao SM, Dubcovsky J, Dvorak J, Luo MC, Baenziger SP, Rustam M, Dale RC, Luther ET, James AA, Susanne D, Karl G, Jianli C, Kim C, Phil LB, Jackie CR, Scott H, Brett FC, Sid P, Mark ES, Eduard DA (2010) Population and genome-specific patterns of linkage disequilibrium and SNP variation in spring and winter wheat (Triticum aestivum L.). BMC Genomics. 11:727.

Chao S, Zhang WJ, Dubcovsky J, Sorrells M (2007) Evaluation of genetic diversity and genome-wide linkage disequilibrium among U.S. wheat (Triticum aestivum L.) germplasm representing different market classes. Crop Sci.47:1018-1030.

Collins NC, Tardieu F, Tuberosa R (2008) QTL approach for improving crop performance under abiotic stress conditions: where do we stand? Plant Physiol. 147(2):469-486.

Cooper M, van Eeuwijk FA, Hammer GL, Podlich DW, Messina C (2009) Modeling QTL for complex traits: detection and context for plant breeding. Curr Opin Plant Biol.12(2):231-240.

Dodig D, Miroslav Z, Borislav K, Jasna S, Vesna K, Steve Q, Jeremy B (2012) Genetic and association mapping study of wheat agronomic traits under contrasting water regimes. Int J Mol Sci. 13(5):6167-88.

Earl DA, vonHoldt BM (2012) STRUCTURE HARVESTER: a website and program for visualizing STRUCTURE output and implementing the Evanno method. Cons Genet Res. 4(2): 359-361.

Edae EA, Patrick FB, Scott DH, Marta SL, Matthew PR (2014) Genome-wide association mapping of yield and yield components of spring wheat under contrasting moisture regimes. Theor Appl Genet. 127(4):791-807.

Fernandez GCJ (1992) Effective selection criteria for assessing plant stress tolerance. In: Proceedings of the international symposium on adaptation of vegetable and other food crops in temperature and water stress. Taiwan. pp. 257-270. 
Flint-Garcia SA, Thuillet AC, Yu J, Pressoir G, Romero SM, Mitchell SE, Doebley J, Kresovich S, Goodman MM, Buckler ES (2005) Maize association population: A high resolution platform for quantitative trait locus dissection. Plant J.44:1054-1064.

Flint-Garcia SA, Thornsberry JM, Buckler ES (2003) Structure of linkage disequilibrium in plants. Annu Rev Plant Biol. 54: 357-374.

Fischer RA, Edmeades GO (2010) Breeding and cereal yield progress. Crop Science. 50:85-98.

Fischer RA (1985) Number of kernels in wheat crops and the influence of solar radiation and temperature. J Agr Sci.105:447-461.

Fischer RA, Maurer R (1978) Drought resistance in spring wheat cultivars. Part 1: grain yield response. Aust J Agr Res. 29:897-912.

Ganal MW, Röder MS (2007) Microsatellite and SNP markers in wheat breeding. In: VarshneyRK, Tuberosa R editors (eds): Genomics application in crops. Vol 2: pp. 124.

Gu J, Xinyou Y, Paul CS, Tjeerd JS, Huaqi W (2011) Using chromosome introgression lines to map quantitative trait loci for photosynthesis parameters in rice (Oryza sativa L.) leaves under drought and well-watered field conditions. J Exp Bot. 63 (1):155-469.

Gulmezoglu N, Alpu O, Ozer E (2010) Comparative performance of triticale and wheat grains by path analysis. Bulg J Agric Sci. 16(4): 443-453.

Guttieri MJ, Stark JC, Brien K, Souza E (2001) Relative sensitivity of spring wheat grain yield and quality parameters to moisture deficit. Crop Sci. 41(2):327-335.

HabashDZ, Bernard S, Schondelmaier J, Weyen J, Quarrie SA (2007) The genetics of nitrogen use in hexaploid wheat: $\mathrm{N}$ utilization, development and yield. Theor Appl Genet. 114(3):403-419.

Hardy OJ, Vekemans X (2002) SPAGeDi: a versatile computer program to analyse spatial genetic structure at the individual or population levels. Mol Ecol Notes. 2:618-620.

Harjes CE, Rocheford TR, Bai L, Brutnell TP, Kandianis CB, Sowinski SG, Stapleton AE, Vallabhaneni R, Williams M, Wurtzel ET, Yan J, Buckler ES (2008) Natural genetic variation in lycopene epsilon cyclase tapped for maize biofortification. Science. 319(5861):330-3.

Huang, XQ, Kemp H, Ganal, MW, Röder, MS (2004) Advanced backcross QTL analysis in progenies derived from a cross between a German elite winter wheat variety and a synthetic wheat (Triticum aestivum L.). Theor Appl Genet. 109(5):933-943.

Khakwani AZ, Dennett MD, Munir M (2011) Drought tolerance screening of wheat varieties by inducing water stress conditions. Songklanakarin J Sci Tenchol. 33(2):135142.

Li ZK, Jiang XL, Peng T, Shi CL, Han SZ, Tian B, Zhu ZL, Tian JC (2014) Mapping quantitative trait loci with additive effects and additive $\mathrm{x}$ additive epistatic interactions for biomass yield, grain yield, and straw yield using a doubled haploid population of wheat (Triticum aestivum L.). Genet Mol Res. 13(1): 1412-1424.

Maccaferri M, Sanguineti MC, Demontis A, El-Ahmed A, del Moral LG, Maalouf F, Nachit M, Nserallah N, Ouabbou H, Rhouma S, Royo C, Villegas D, Tuberosa R (2011) Association mapping in durum wheat grown across a broad range of water regimes. J Exp Bot. 62(2):409-38.

Maccaferri M, Sanguineti MC, Corneti S, Ortega JL (2008) Quantitative trait loci for grain yield and adaptation of durum wheat (Triticum durum Desf.) across a wide range of water availability. Genetics. 178(1):489-511.
McCartney CA, Somers DJ, Humphreys DG, Lukow O, Ames N, Noll J, Cloutier S, McCallum BD (2005) Mapping quantitative trait loci controlling agronomic traits in the spring wheat cross RL4452 x 'AC Domain'. Genome. 48(5):870-883.

McIntyre CL, Mathews KL, Rattey A, Chapman SC, Drenth J, Ghaderi M, Reynolds M, Shorter R (2010) Molecular detection of genomic regions associated with grain yield and yield-related components in an elite bread wheat cross evaluated under irrigated and rainfed conditions. Theor Appl Genet. 120(3):527-41.

Mir R, Zaman-Allah M, Sreenivasulu N, Trethowan R, Varshney R (2012) Integrated genomics, physiology and breeding approaches for improving drought tolerance in crops. Theor Appl Genet. 125(4):625-45.

Neumann K, Kobiljski B, Dencic S, Varshney RK, Börner A (2011) Genome-wide association mapping: a case study in bread wheat (Triticum aestivum L.). Mol Breeding. 27:3758.

Nezhad KZ, Weber WE, Röder MS, Sharma S, Lohwasser U, Meyer RC, Saal B, Börner A (2012) QTL analysis for thousand-grain weight under terminal drought stress in bread wheat (Triticum aestivumL.). Euphytica.186:127-138

Nouri A, Etminan A, Jaime A, Silva TD, Mohammadi R (2011) Assessment of yield, yield related traits and drought tolerance of durum wheat genotypes (Triticumtrugidum var. durumDesf.). Aust J Crop Sci. 5(1):8-16.

Osipova S, Alexey P, Marina P, Talyana P, Vasiliy V, Alexandr R, Elena R, Alexandr S, Alexey D, Andreas B (2016) Regions of the bread wheat D genome associated with variation in key photosynthesis traits and shoot biomass under both well watered and water deficient conditions. J Appl Genet. 57(2):151-63.

Peng JH, Bai Y, Haley SD, Lapitan NLV (2009) Microsatellite-based molecular diversity of bread wheat germplasm and association mapping of wheat resistance to the Russian wheat aphid. Genetica. 135(1):95-122.

Prince SJ, Beena R, Gomez SM, Senthivel S, Babu RC (2015) Mapping consistent rice (Oryza sativa L.) yield QTLs under drought stress in target rainfed environments. Rice. $8: 25$.

Pritchard JK, Stephens M, Donnelly PJ (2000) Inference of population structure using multilocus genotype data. Genetics. 155(2):945-959.

Quarrie SA, Steed A, Calestani C, Semikhodskii A, Lebreton C, Chinoy C, Steele N, Pljevljakusic D,Waterman E, Weyen J, Schondelmaier J, Habash DZ, Farmer P, Saker L, Clarkson DT, Abugalieva A, Yessimbekova M, Turuspekov Y, Abugalieva S, Tuberosa R, Sanguineti MC, Hollington PA, Aragues R, Royo A, Dodig D (2005) A high density genetic map of hexaploid wheat (Triticum aestivum L.) from the cross Chinese Spring 9 SQ1 and its use to compare QTLs for grain yield across a range of environments. Theor Appl Genet. 110(5):865-880.

Reynolds M, Pask A (2012) Physiological breeding I: interdisciplinary approaches to improve crop adaptation. CIMMYT: Mexico, DF, Mexico, ix, 174 pages

Saghai-Maroof MA, Soliman KM, Jorgensen RA, Allard RW (1984) Ribosomal DNA spacer length polymorphisms in barley: mendelian inheritance, chromosomal location, and population dynamics. Proc Natl Acad Sci USA.81:80148018.

Salekdeh GH, Reynolds M, Bennett J, Boyer J (2009) Conceptual framework for drought phenotyping during molecular breeding. Trends Plant Sci. 14(9):488-96.

SAS Institute (2001) The SAS system for Windows, Release 8.01, SAS Inst., Cary, NC, USA. 
Sinclair TR (2012) Is transpiration efficiency a viable plant trait in breeding for crop improvement? Funct Plant Biol. 39(5): 359-365.

Snape JW, Foulkes MJ, Simmonds J, Leverington-Waite M, Fish LJ, Wang Y, Ciavarrella M (2007) Dissecting gene x environmental effects on wheat yields via QTL and physiological analysis. Euphytica.154(3):401-408.

SPSS Inc., 2007. SPSS for Windows, Release 16.0.SPSS Inc., Chicago, IL, USA.

Sun XY, Wu K, Zhao Y, Kong RM, Han GZ, Jiang HM, Huang XJ, Li RJ, Wang HJ, Li SS (2009)QTL analysis of kernel shape and weight using recombinant inbred lines in wheat. Eupytica.165:615-624.

Wang LF, Ge HM, Hao CY, Dong YS, Zhang XY (2012) Identifying loci influencing 1,000-kernel weight in wheat by microsatellite screening for evidence of selection during breeding. PLoSONE, 7(2).
Wen W, Mei HW, Feng FJ, Yu SB, Huang ZC, Wu JH, Chen L, Xu XY, Luo XJ (2009) Population structure and association mapping on chromosome 7 using a diverse panel of Chinese germplasm of rice (Oryza sativa L.), Theor Appl Genet. 119(3):459-70.

Yu J, Zhang Z, Zhu C, Tabanao DA, Pressoir G, Mitchell RT, Stephen K, Rory JT, Edward SB (2009) Simulation appraisal of the adequacy of number of background markers for relationship estimation in association mapping. Plant Genome. 2(1):63-77.

Zwart RS, Muylle H, Bockstaele E, Roldán-Ruiz I (2008) Evaluation of genetic diversity of Fusarium head blight resistance in European winter wheat. Theor Appl Genet. 117(5):813-28. 